doi: $10.15503 /$ jecs2021.1.335.345

\title{
LEARNING CONTINUITY DURING COVID-19 PANDEMIC USING THE VIRTUAL CLASSROOM - A CROSS-BORDER EXPERIMENTAL MULTI-CASE APPROACH
}

\author{
KHANDAKAR KAMRUL HASAN \\ Department of Business Management, Tripura University (A Central Univer- \\ sity), Suryamani Nagar, Agartala, Tripura 799022, India \\ Email address: kkhasan@gmail.com \\ ORCID: https://orcid.org/0000-0002-2462-1165 \\ DEBARSHI MUKHERJEE \\ Department of Business Management, Tripura University (A Central Univer- \\ sity), Suryamani Nagar, Agartala, Tripura 799022, India \\ Email address: debarshimukherjee@tripurauniv.in \\ ORCID: https://orcid.org/0000-0001-9039-0329

\section{MAHASWETA SAHA} \\ Department of Business Management, Tripura University (A Central Univer- \\ sity), Suryamani Nagar, Agartala, Tripura 799022, India \\ Email address: mahasweta_saha@tripurauniv.in \\ ORCID: https://orcid.org/0000-0002-6131-8456
}

\begin{abstract}
Aim. The global pandemic of the COVID-19 and the subsequent nationwide lockdown have put the endeavours of both academicians and students to the test. The disruptions are even visible in andragogical approaches across higher education institutions both nationally and internationally. Two government-funded universities in India and Bangladesh have decided to explore avenues to switch to an alternative e-platform overcoming the challenges of traditional classroom teaching. The business management faculties of both universities exercise blended learning modules using a design thinking approach.

Methods. This exploratory case study involves university students and teachers reflecting on the knowledge delivery mechanism in a collaborative online workspace called the virtual classroom. The authors have adopted the case method to identify evidence-based practices improving learning gains. This case is motivated by the profound idea of learning continuity where the agenda of teaching-learning should remain status quo as much as possible, even under the constrained situation.
\end{abstract}


Results and conclusions. This study confirms that the use of curriculum-based blended learning modules applying a design thinking approach is gaining momentum to offer courses in which videoconferencing is a useful tool as an addition to present methods of teaching inside the classroom, to strengthen learning and to inspire students to practice learning. Acceptance of technology has made learning accessible and pervasive, bridging the digital divide.

Originality. It is a pioneering effort to measure the effectiveness of the online learning of two public-funded universities across borders with similar demographics and challenges. This case makes an original contribution through its observation that even the traditional and public-funded universities erstwhile functioning through purely offline mode are gradually switching to online mode. This case also highlights the imminent need for policymakers to augment and integrate blended learning tools with design thinking approaches for tertiary education to reduce the intermittent use of technology, thereby assuring higher learning gain for the students.

Key words: virtual classroom, e-learning, blended learning, design thinking, learning gain

\section{INTRODUCTION}

$\mathrm{T}$

he worldwide pandemic of COVID-19 has sent shock waves through humanity and made us stand onthe brink of disruptive volatility, both financially and socially. One does not necessarily need to commute to compute. Be it classes and/or business meetings, all are extensively using digital platforms (e.g. video conferencing), regardless of geographical positioning, and/or private or government sectors. True, that the andragogic approaches of online learnin$\mathrm{g} / \mathrm{e}$-learning started gaining momentum about two decades back; however, its usage has been intermittent, thereby causing heavy reliance on formal face-to-face teaching. The proponents of e-learning practices envisaged a ubiquitous learning environment, where students can learn undeterred. Unfortunately, even today in India, e-learning has not been able to draw a parallel to formal classroom teaching. Instead, the approach of a technology-mediated learning environment has remained as an auxiliary support system to the traditional chalk and talk mechanism (Gaikwad \& Randhir, 2016). The nascent idea of ubiquity in the process of learning has been replaced by a neo-practice of learning continuity under education 4.0, where the curriculum demands augmentation of virtual learning prescriptions to be embedded within the university system of education. In designing an e-learning system, it is essential to enhance creative thinking by including innovative teaching methods (Songkram, 2015). Thus, our paper develops a teaching support intervention system, which could be implemented within a virtual environment of classroom teaching.

Under the forced lockdown due to the COVID-19 epidemic, both teachers and students have been facing the psychological trauma of dealing with the fear of the unknown, while trying to acclimatise themselves to a new learning environment, which in itself seems to pose a significant challenge. Thus, design thinking is a newly emerging and globally accepted approach to deal with complex problems, where teams face varied challenges. Solution prototypes are deve- 
loped through creativity, critical thinking, and communication with the assessment of scalability fostering innovation. Design thinking could be described as a system of spaces where different sorts of related activities form a continuum of innovation; it seems chaotic for those experiencing it the first time. Apart from the challenges related to the technological aspects of the new learning environment, the bigger challenge for the teachers has been to establish the "connection" with their students on a virtual platform and teach as effectively as in their classrooms. The educators following the design thinking approach continue to support the students to develop an insight into the challenges of business design.

Given this background, the present study employs the design thinking approach and a teaching support intervention system that has been initiated in two universities (India and Bangladesh) because, in recent years, both the Department of Business Management at Tripura University and the Institute of Business Administration, University of Dhaka, have conjointly been advancing existing processes by introducing new virtual class practices through experimenting with design thinking. Interestingly, both departments chose to shun the ad-hoc use of technology and instead chose to adopt a heutagogical approach to blending two maxims of learning, while ensuring higher learning gain. This paper examines the application of web-based video conferencing classrooms and explores the perception of the students towards the blended learning approach adopted by the two departments. Blended learning has been a focus of attraction in academia due to the infusion of interactive-media technology and hassubstance for the educational fraternity at a global level and transformative development of various pedagogical approaches for optimising learning of the students (Mukherjee, 2012a). A virtual class emphasises the innovative design thinking capability of the students, coupled with their ability to use technology effectively. The methodology for this study comprises a theoretical framework, while the empirical basis consists of data generated in virtual classes for design thinking, coupled with experiences from teachers supervising the students' learning process. Notably, attempts have been made to perceive design thinking as a form of adductive thought in light of its capacity to generate out-of-the-box ideas (Cross, 2006; Dorst, 2011).

The main objective of this study was to understand the students' responses to design thinking as an approach to online learning (Mostofa, Othman, Mukherjee, \& Hasan, 2020). The context of the study is interesting as for any publicly funded university in India or Bangladesh, the teaching method so far has intermittent or no technology intervention due to various reasons. However, due to the COVID-19 outbreak, and the consequential lockdown measures, universities were almost compelled to opt for the online mode of learning to support learning continuity. Thus, we feel that the struggle of both the teachers and students alike of erstwhile offline departments to move online is worth looking into for exploring if this could be a new norm in education. The initial surveys on the frequency and patterns of videoconferencing provided reference information for selected case studies involving in-depth interviews with key staff participating in the implementation of videoconferencing and video streaming observa- 
tions of lessons being used. Analysis of data shows that the main videoconferencing models used both "replacement" (of face-to-face instruction delivery) and "improvement" (of conventional pedagogical practices). Herein, empathy naturally results in accessible, human-centred design. However, an approach to design thinking and humanistic design, as applied to e-learning, focuses on designing solutions that work for real learners under real workday situations. The method produces secondary qualitative data based on virtual classes in Tripura and Dhaka; for instance, interpretations, understanding, and perceptions, which aim at producing a "contextual" understanding of experiences, rather than verifiable results. This paper discusses design thinking for business management students, a practical learning approach to create an ideal university for future leaders by adopting aspects of blended teaching methods.

This case-based experimental research study has several theoretical and practical contributions. This research work aims to investigate the effectiveness of the e-learning framework within the virtual learning environment to build videoconferencing classrooms for higher education learners. This research applied an experimental teaching method to incorporate design thinking. First, this is the first-ever case that employed design thinking and a cross-border experimental approach across one of the Indian and Bangladesh universities to understand the effectiveness of the e-learning framework. The real-time feedback on the performance of the virtual learning platform for videoconferencing and on the transportation network was gathered. Second, the comments and impressions of the students from these learning sessions were analysed through multiple literature reviews and question-based surveys, which provided valuable insights and immensely contributed to the growing body of literature on design thinking and learning continuity. Third, the integration of Moodle LMS with online classes in the Department of Business Management at Tripura University and a similar approach at the Institute of Business Administration at Dhaka University have elevated the andragogic infrastructure, independent of a physical classroom, thereby ensuring learning continuity ubiquitously. Fourth, this case-based experimental approach and the outcomes of this study may help future researchers in the area of higher education, especially in developing economies like India and Bangladesh. Future research studies can focus on adopting the same framework at a larger scale for the generalisation of the findings and may report on any other challenges.

\section{BACKGROUND OF THE STUDY}

Virtual classrooms are essentially based on the learning theory of "connectivism," appropriate for the digital age (Kop \& Hill, 2008) and supporting networked learning interactions. They are accessible and decentralised; herein, the learner decides his or her aims, processes, and outcomes. Virtual classroom at a graduate-level learning has been evolving quickly, so have societal technology applications and ways in which both the teachers and students access information (Bates, 2005; Kruger-Ross \& Waters, 2013; Moore, 1989). In this study, we 
look at how conversations about designing online, the role of design in itself, and the challenges of information overload for the students may help educators identify evidence-based practices to improve essential elements of practical educational technology design. If we are to develop design thinking ability in individuals whose experience encompasses numerous disciplines and practices, we need new learning approaches. Current technologies have led to new online educational channels, including architecture (Dreamson, 2017).

\section{LITERATURE REVIEW}

\section{Design thinking education}

Design thinking has become common in various disciplines, as its techniques and methods are often synonymous with creativity (Dong, 2015). Universities are increasingly integrating design thinking into their curricula (Matthews \& Wrigley, 2017). Long-established components of any programme in a design discipline, as well as courses in design thinking are popular in business and management education. Design thinking courses also involve cohorts of students from a variety of disciplines - such as engineering, social sciences, industry, medicine, and education - to solve actual, complex problems using a human-centred design approach (Wrigley \& Straker, 2017). In addition to promoting trans-disciplinary innovative thinking and collaboration, cross-disciplinary student enabling can overcome specific knowledge gaps (Razzouk \& Shute, 2012).

\section{Design thinking in e-learning}

Design thinking is a problem-solving method that helps to consider a dilemma posed by a learner or organisation and then come to a consensus as to how the problem could be solved using e-learning tools. Design thinking and human-centred design are approaches applied to e-learning; they focus on designing solutions that work for real learners in real workday situations. Empathy is the first stage in the process, followed by "define," "ideate," "prototype," and "test." The design thinking approach arose as a response to the growing complexities of modern business and technology (Rosenberg, 2005). In technology, for instance, the focus on user-centric design makes complex systems less complicated, instinctive, and enjoyable. To build sensitive and impactful learning experiences, a set of five principles should be applied to e-learning.

Principle 1: Research the emotional response of the learner

Focus on memories that establish empathetic relationships with learners. Emotion is another important factor in the analysis of focus (Nunley, 2012).

Principle 2: Model the study of complex problems

Design thinking has been increasingly applied to complex and intangible issues (e.g. how does an instructor understand that our students have learned to deliver any concept or topic?)Besides, it helps nonlinear thinking to evolve when solving nonlinear problems. 
Principle 3: Exploring alternative approaches using prototyping (Luecke, 2003)

Prototypes may be mechanical, physical, or illustrative; but they are a way of communicating with a concept. By expressing one's interest in prototyping innovation and creativity, one could turn a concept into something genuinely special and worthwhile.

Principle 4: Tolerate a mistake

Design thinking does not promote failure, but it admits that it is difficult to get it right for the first time. Leveraging fault as learning is the ethos of design thinking.

Principle 5: Show restraint

Possibly, scholars are all too familiar with what their e-learning system should provide, and just as importantly, what it does not include.

In Educational Benefits of Online Learning (n.d.), some of the educational benefits of incorporating Web-based resources into a course are listed:

- strengthening intercommunication between learner-to-learner and instructor-to-learner;

- allowing student-centred pedagogy techniques;

- making course instruments available 24/7;

- providing tools for measuring and reviewing student progress in just-in-time technique;

- reducing resources around the organisation of courses.

\section{FEATURES OF VIRTUAL CLASSROOM IN DESIGN THINKING}

Technology has invaded every domain of life and its use increased during the COVID-19 pandemic in order to reduce the risk of infection. For instance, with the onset of software packages and the use of ERP systems, students of management discipline are no longer required to prepare balance sheets, journals, and trial balances manually (Dey, 2007). Further, teachers can choose from various types of online classrooms that are readily accessible to users e.g., Moodle Cloud, Skype, Google Classroom, Microsoft Team, Google Meet, Zoom, etc. However, educators must make sure that all the features available to facilitate student interaction and learning are in the virtual classroom they have selected as a teaching aid. The powerful features that are available in the virtual classrooms include audio, video, tools for sharing files, online grading, and group chatting, which are essential to provide a virtual learning environment. In reality, some virtual classrooms have features that encourage communication among the participants using annotation and whiteboard tools. Moreover, an integrated system for digital education can be used for different purposes including support for learning, communication, administration, and teachers (Mukherjee, 2014). Principally, a virtual classroom can be of assistance to teachers in several ways; for instance, 
it saves time in allowing teachers to organise their teaching resources and materials. It is therefore an ideal platform to enhance both workflow and efficiency for teachers. There are several curriculum management systems for all users, which are free and readily available online. Virtual classrooms are environmentally friendly, as teachers can collect assignments and materials online, which eliminates the need to use paperwork. They offer learners both flexibility and mobility; the students can use the device-independent resources available on the cloud ubiquitously. The virtual classroom often helps the students who come from far-flung and remote areas and may find it challenging to attend lectures regularly in the physical classrooms. Importantly, there is enough room in other curriculum information systems; there is an appropriate, limitless research facility that helps users to deposit their research in paperless form for an extended period. The electronic monitoring system may be used by faculties to recognise which students in the class require more assistance. When using the online grading tool, students' work can be measured, and the grades can be automatically submitted within the program. Hence, the virtual classroom also simplifies the course instructor's grading structure. In most cases, virtual classes are user-friendly; thus, both teachers and students can easily use the program without any formal training.

\section{BENEFITS OF THE VIRTUAL CLASSROOM IN DESIGN THINKING}

About 20 years ago, the implementation of the virtual classroom facility into the education system was rapidly recognised as having the ability to solve many higher education issues. Specifically, in the context of both India and Bangladesh, teachers have been compelled to embrace technology in teaching. Synchronous online classrooms are quite popular with teachers as they facilitate real-time communication with the learners (Martin \& Parker, 2014). Google Classroom is a commonly used example of a virtual learning management program, which was introduced in May 2014. Herein, a teacher opens particular classrooms, comprising of various sections and subjects. The following facilities are offered by a virtual classroom platform (Bower, 2006):

- class presentation distribution - PowerPoint;

- screen sharing - full desktop, device, or monitor with remote control;

- webcam - different speeds, streaming capacity;

- VoIP - customisable level of transmission to match the link;

- message chat - send to all or selected persons;

- whiteboard - the capabilities of various colours/fonts/transparency rates, drag-and-drop, undo, and paper overlay;

- download/upload files - picked from device or web repository;

- polling - with links to individual answers by the presenter;

- list of participants - including status indicator ("fine," "slower" etc.);

- browser launcher - opens the same URL for all users;

- notepad - summarising, including guidance, etc. 


\section{CHALLENGES OF THE VIRTUAL CLASSROOM}

Perceived issues with the video-conferencing facility in educational settings are related to accessibility and pedagogy. One of the primary issues with videoconferencing is its inflexible dependency on technology. Thus, at times where technology fails, there is no other solution to fall back upon instantly (Gillies, 2008).In our case, both Tripura University and Dhaka University's goal has been to build an immersive, virtual videoconferencing classroom that would assist both teachers and students. Amid this pandemic, universities and academic institutions are scrambling to come up with innovative ideas to minimise such issues, while maintaining the integrity and purpose of simulating a face-to-face classroom (Wedig, 2010). These various ideas and methods do provide a comprehensive picture of the range, nature, and impact of learning in the respective universities/institutions. However, ideas demand investments; investments in building/upgrading to a robust ICT infrastructure, related to creating professional development programmes for teachers, and in building a curriculum management of learning. Moreover, such virtual classrooms require teaching methods to be adaptable, as even the teacher needs to upgrade his or her professional skills, learn new teaching techniques, and adapt the current curricula to the modern learning environment (Mukherjee, 2012). Despite having many positives, the infrastructural bottleneck is a major impediment for the success of the online approach to teaching and the digital divide among the students disrupts the learning experience to some extent. However, the issues at the user end do not concur as far as the methodology of online classes is concerned.

Besides, the Department of Business Management (Tripura University) and the Institute of Business Administration (Dhaka University) were granted the independence of management and the opportunity to innovate, as well as the determination to co-operate with new initiatives. The students' reports about the virtual classroom exploits have been overwhelmingly positive - "hard to listen, difficult but challenging," "interesting and wanting more," "never had learning opportunities through the virtual classroom," "give us more time for evaluation task," and so on. A summary of challenges in the teaching and learning process using design thinking is presented below (see Table 1). The challenges are categorised into four domains - technical, organisational, occupational, and social. Real-time virtual classroom experiences are shared with evidence provided for each of the experiences.

\section{OBJECTIVES AND METHODOLOGY}

In the context of this literature review, two key issues for virtual classrooms were extracted from research literature: teaching methods and active student participation. The goal of this research was to study the e-learning framework within the virtual learning environment to build videoconferencing classrooms for higher education learners. This research applied an experimental teaching method to incorporate design thinking. Tripura University began its virtual clas- 
Journal of Education Culture and Society No. 1_2021

Table 1

Challenges: teaching and learning in design thinking

\begin{tabular}{|c|c|c|c|}
\hline Challenges & $\begin{array}{l}\text { Virtual classroom } \\
\text { experiences }\end{array}$ & Evidence & Source(s) \\
\hline $\begin{array}{l}\text { Technical } \\
\text { challenges }\end{array}$ & $\begin{array}{l}\text { Attitude and aptitude } \\
\text { towards technology }\end{array}$ & $\begin{array}{l}\text { The effect e-learning has } \\
\text { on novice users. They pro- } \\
\text { mote information sharing } \\
\text { with teachers and within } \\
\text { the department. }\end{array}$ & $\begin{array}{l}\text { Edwards } \\
(2018)\end{array}$ \\
\hline \multirow[t]{3}{*}{$\begin{array}{l}\text { Organisatio- } \\
\text { nal challen- } \\
\text { ges }\end{array}$} & $\begin{array}{l}\text { Easy to contact a cour- } \\
\text { se teacher for a virtual } \\
\text { lecture. }\end{array}$ & $\begin{array}{l}\text { Students receive imme- } \\
\text { diate feedback and they } \\
\text { are allowed to contact } \\
\text { their instructor in the co- } \\
\text { urse easily. }\end{array}$ & $\begin{array}{l}\text { Peytcheva- } \\
\text { Forsyth, } \\
\text { Yovkova, } \\
\text { \& Aleksie- } \\
\text { va(2018) }\end{array}$ \\
\hline & $\begin{array}{l}\text { Teachers are motiva- } \\
\text { ted to embrace new } \\
\text { pedagogies and switch } \\
\text { from teacher-centric } \\
\text { approaches to student- } \\
\text {-centred approaches to } \\
\text { teaching and learning. }\end{array}$ & $\begin{array}{l}\text { To build a more immer- } \\
\text { sive and collaborative } \\
\text { learning environment, te- } \\
\text { achers are made to rebuild } \\
\text { and redesign their courses } \\
\text { and integrate virtual clas- } \\
\text { srooms in all classes. }\end{array}$ & $\begin{array}{l}\text { Roussos et } \\
\text { al. (1997) }\end{array}$ \\
\hline & $\begin{array}{l}\text { University adopting } \\
\text { the latest virtual lear- } \\
\text { ning community, and } \\
\text { greatly developing the } \\
\text { digital infrastructure. }\end{array}$ & $\begin{array}{l}\text { During the pandemic } \\
\text { situation of COVID-19, } \\
\text { universities accepted their } \\
\text { first community of virtual } \\
\text { learning students from } \\
\text { March } 2020 \text { and were } \\
\text { determined to deliver a } \\
\text { full-time educational expe- } \\
\text { rience. }\end{array}$ & $\begin{array}{l}\text { Mukherjee \& } \\
\text { Hasan (2020) }\end{array}$ \\
\hline $\begin{array}{l}\text { Occupatio- } \\
\text { nal challen- } \\
\text { ges }\end{array}$ & $\begin{array}{l}\text { Teachers need to learn } \\
\text { new ways of commu- } \\
\text { nicating with the stu- } \\
\text { dents. The emphasis } \\
\text { should be on learning } \\
\text { and not on teaching, } \\
\text { and teachers should } \\
\text { reformulate their posi- } \\
\text { tion accordingly. }\end{array}$ & $\begin{array}{l}\text { Teachers monitor student } \\
\text { attendance during the } \\
\text { virtual class in a self- } \\
\text {-styled e-learning form, } \\
\text { scheduling virtual classes } \\
\text { from anywhere during } \\
\text { the day and documenting } \\
\text { their interactions during } \\
\text { the lectures. }\end{array}$ & Suh (2011) \\
\hline $\begin{array}{l}\text { Social chal- } \\
\text { lenges }\end{array}$ & $\begin{array}{l}\text { Learners feel active } \\
\text { and confident in es- } \\
\text { tablishing a sense of } \\
\text { identity in society. }\end{array}$ & $\begin{array}{l}\text { Students know the techno- } \\
\text { logy but are still unfami- } \\
\text { liar with taking an active } \\
\text { part in education. }\end{array}$ & $\begin{array}{l}\text { Settles } \\
(2012)\end{array}$ \\
\hline
\end{tabular}

Source: literature review 
ses from the Department of Business Management with over 160 participants from the business and tourism administration discipline whereas the Institute of Business Administration of Dhaka University began the virtual class with over 200 participants and both institutes taught students from undergraduate as well as postgraduate discipline. Students who were interested in attending the classes during the lockdown period (i.e. from both Tripura and Dhaka Universities respectively) could login through a videoconferencing application to start their mid-semester classes, while teachers could update the class conduct methods and learning activities within their course materials. However, the key issues that both of these universities faced were how to keep teachers linked amongst themselves and with their students. How to ensure that the teachers could smoothly engage with their learners, especially the ones who may be struggling; and how to turn students from being completely teacher-dependent to being self-driven and autonomous, whereby they could communicate with their teachers and peers independently. The goal of this research has thereby been to assess the performance of e-learning students as opposed to conventional face-to-face students taught by the same teacher. A videoconference classroom experience assessment was performed using qualitative and quantitative methods. Additionally, we conducted group interviews in which we asked about students'opinion concerning different aspects of the virtual classroom, such as the relationship between time spent and benefits, along with an open-ended question about the potential changes in that classroom which have brought in their learning experience. The e-learning framework for integrating design thinking for higher education learners in the interactive learning environment consisted of: 1 ) empathy for the learners;2) identification of learning objectives;3) identification of reality;4) identification of ideas;5) identification of the problems and their subsequent solutions;6) development of productive content;7) assessment;8) learner acceptance. The comments and knowledge of the students from these learning sessions were evaluated through several survey-based questions. Since subjective metrics are not easy to achieve, these questions focused on two aspects: the general perception of the "new" approach, the use of videoconferencing in the actual learning session; and the perception students have of the technical quality of the learning sessions (quality of audio/video, instructional material, etc.). Our analysis has been sociological, as it deals with the potential implementation of information and communication technology (ICT) vis-a-vis the social effect of the process at large. Moreover, it also includes different types of research and categories such as: a) case studies, closely examining the actual application of the virtual learning approach based on videoconferencing during the project; $b$ ) assessment surveys, produced and evaluated by researchers for teaching and learning.

The virtual classroom interactive approach tackles the key problem of distance education, namely the participation of the students, which can be used online with mixed instructional settings (Parker \& Martin, 2010). We conducted extensive literature reviews to find similar documents and papers on virtual education in design thinking, primarily hinging on journals, academic papers, and webpages. 


\section{SAMPLE AND DATA COLLECTION}

The case study is focused on data collected from two well-known universities using the students' classroom devices for virtual videoconferencing. Its aim is to suggest a research model that supports the effective application of the classroom resources for virtual videoconferencing from the best practices gained from both Tripura and Dhaka universities. Considering that the universities selected represent the local and global presence, and function geographically in India and Bangladesh, a standardised model would certainly be necessary to unleash the standards of practice from an international perspective. All the teachers who had been using the classroom on virtual videoconferencing for some time were optimistic about their educational potential, citing several advantages for pupils. These include changes in (Lawson \& Comber, 2005):

- motivation,

- learning participation,

- topic awareness and comprehension,

- talking and listening,

- retention of details,

- social and communication skills,

- knowledge of other cultures.

Additionally, some teachers indicated that these changes had been sustained beyond the immediate experience of the virtual videoconference classroom, especially trust in open discussions, for some pupils.

\section{SUCCESSFUL IMPLEMENTATION OF THE VIRTUAL CLASSROOM TOOLS IN THE DESIGN THINKING PROCESS: CASE STUDIES}

The design approach is what gives meaning to design thinking. It is a systematic approach to create and evolve ideas. It is a deeply humanistic approach that depends on our opportunity to be intuitive, to understand what we experience, and to create ideas that are emotionally relevant to those for whom we design - all skills that we are well versed in as educators (IDEO, 2013).

This paper highlights the endeavours of two departments of two different public-funded universities, i.e. Department of Business Management at Tripura University of India and Institute of Business Administration at Dhaka University in Bangladesh. There is a demographic similarity among the students, as both departments enrol them in their respective countries with a forward-thinking approach. Similar student profiles have brought the two departments to a pedestal where technology intervention vis-a-vis its subsequent response may be evaluated for a better understanding of technology acceptance among the students across borders. Despite having a series of challenges, the humble background of most of the students and infrastructural bottlenecks tend to create a major impediment to learning online. 


\section{ANALYSIS}

Below is an exhaustive summary of our case. This detailed summary would help in creating the proposed research model (see Table 2). Table 2 delineates the problems identified while implementing virtual classroom videoconferencing systems in both universities and provides the solutions to ensure learning continuity.

Table 2

Summary of the virtual classroom videoconferencing systems implemented by the universities

\begin{tabular}{|c|c|c|}
\hline Case instance & Problems identified & $\begin{array}{l}\text { The solution to } \\
\text { ensure learning } \\
\text { continuity }\end{array}$ \\
\hline \multirow{3}{*}{$\begin{array}{l}\text { Department of } \\
\text { Business Manage- } \\
\text { ment, Tripura Uni- } \\
\text { versity, India }\end{array}$} & $\begin{array}{l}\text { Teachers and students were } \\
\text { unaware of the technology } \\
\text { and were apprehensive about } \\
\text { the response to online classes. } \\
\text { A rigorous timetable could } \\
\text { not be followed due to unsta- } \\
\text { ble Internet bandwidth. }\end{array}$ & $\begin{array}{l}\text { Multiple training sessions were } \\
\text { organised for teachers, who in } \\
\text { turn trained the students. The } \\
\text { counselling session for the stu- } \\
\text { dents mitigated the apprehen- } \\
\text { sions. The attendance percenta- } \\
\text { ge in the classes shot up. }\end{array}$ \\
\hline & $\begin{array}{l}\text { Excessive data usage caused } \\
\text { additional expenditure. }\end{array}$ & $\begin{array}{l}\text { Time for each online lecture was } \\
\text { reduced and the timetable was } \\
\text { made more spacious to acclima- } \\
\text { tise with the new setting, which } \\
\text { in turn reduced the expenditure } \\
\text { on data packs. }\end{array}$ \\
\hline & $\begin{array}{l}\text { Tests and assignments admi- } \\
\text { nistration were asynchronous } \\
\text { and were cluttering the email } \\
\text { inbox. }\end{array}$ & $\begin{array}{l}\text { All tests and assignments were } \\
\text { submitted through Moodle } \\
\text { LMS, which not only reduced } \\
\text { email clutters but also provided } \\
\text { a data repository and visualisa- } \\
\text { tion of data. }\end{array}$ \\
\hline \multirow{3}{*}{$\begin{array}{l}\text { Institute of Busi- } \\
\text { ness Administra- } \\
\text { tion, Dhaka Univer- } \\
\text { sity, Bangladesh }\end{array}$} & $\begin{array}{l}\text { Shared times for both students } \\
\text { and teachers are more difficult } \\
\text { to plan. }\end{array}$ & $\begin{array}{l}\text { Immediate personal engage- } \\
\text { ment between students and } \\
\text { teacherscreates a greater sense } \\
\text { of community and lessens the } \\
\text { feeling of isolation. }\end{array}$ \\
\hline & $\begin{array}{l}\text { Many students have faced } \\
\text { technological difficulties or } \\
\text { problems when they do no- } \\
\text { thave fast or efficient Wi-Fi } \\
\text { networks. }\end{array}$ & $\begin{array}{l}\text { More open contact between } \\
\text { students and instructors pre- } \\
\text { vents miscommunication or } \\
\text { confusion. }\end{array}$ \\
\hline & $\begin{array}{l}\text { Students and teachers are } \\
\text { unaware of uploading sub- } \\
\text { missions, formal written as- } \\
\text { signments, and projects thro- } \\
\text { ugh the canvas site. }\end{array}$ & $\begin{array}{l}\text { Multiple training sessions were } \\
\text { held to educate the teachers, } \\
\text { who in turn educated the stu- } \\
\text { dents in the useof the virtual } \\
\text { canvas site. }\end{array}$ \\
\hline
\end{tabular}

Source:authors 
Between these two universities, we noticed that most students liked the discussions and screen-sharing option in the virtual classroom. They also found the accessibility feature attractive because they could access it from anywhere at any time. However, different time zones posed an additional logistical challenge for the international students. Teachers were motivated to embrace modern andragogy and switch from teacher-centric approaches to student-centric approaches in both teaching and learning. To create a more immersive and collaborative learning atmosphere, teachers have also been encouraged to update their courses, and integrate the virtual classrooms into a Learning Management System (LMS) platform, which could carry the recorded lectures for slow learners. The framework for videoconferencing incorporated point of presence devices at each remote site through the interconnecting devices. This was specifically designed to structured protocols (for signalling videoconferencing, audio/video sources, etc.) so that it could be highly scalable and reliable to provide the required output during interactive sessions. The departments used Zoom Meeting Application for communication and collaboration. Zoom has many advantages over other software solutions (Parkinson, 2018). As we realised that our students were able to see every participant in the gallery show, there was no need to substantiate the learner's identity taking the lesson. Many of our learners created their Zoom accounts during the classes so that they could also host their classes as a part of their everyday life at university. Zoom allows the hosts to record their lectures and all interactions in the local drive. The Basic Plan thereby allowed us to teach classes for 40 minutes at no cost. Such intervals of 40 minutes worked well to upload the recordings to the Learning Management System (LMS) without any major changes required to speed up the upload period.

The effect of the live interactive videoconferencing classroom was visible from the results of continuous assessment and class interaction. Psychologically, there is a "backbencher" in an online class that creates a sense of equality among the students which is motivating for them. Students had two main opinions: 1) participating in live interactive videoconferencing classroom for synchronous learning; 2) serving as important factors in the achievement of the students' asynchronous learning through the recorded live lectures held in the digital classroom at any time. The main benefit of the live virtual classroom is that it allows for two-way contact between the teacher and students (Jonassen \& Reeves, 1996).

\section{FUTURE TRENDS}

The incorporation of videoconferencing sessions into the learning and teaching world has set a new trend for "blended" lectures by incorporating a conventional face-to-face approach and interactive method of learning. The virtual classroom has shown that Tripura University's videoconferencing and blended learning has a strong growth potential while offering different 
concept aimed to refresh academic practices. As the results showed, most students were able to identify their respective capabilities for collaborative learning easily, welcome the opportunity to collaborate with a different group of students, and demonstrate a clear preference for the new methodologies. Besides, when videoconferencing is used in combination with other interactive technology, such as whiteboards, shared screens, and shared control, these educational videoconferencing systems can provide high-quality distance education. With the use of smart mobile devices (tablets, smartphones), it can be easily incorporated for improved mobility and agility of the students. The creation of a robust videoconferencing platform in Tripura has allowed the universities in this area to enter the educational activity, which could very soon become an integral part of virtually every class.

\section{DISCUSSION}

This research work aims to investigate the effectiveness of the e-learning framework within the virtual learning environment to build videoconferencing classrooms for higher education learners. The methodology used in this study is adopted because technology enables the transmission of knowledge through videoconferencing, video and text, and online assessments (Mukherjee \& Hasan, 2020). This research applied an experimental teaching method to incorporate design thinking. This learning mechanism is appropriate during and after the COVID-19 pandemic as it helps maintain physical distancing and reduces the risk of infection. The learning mechanism used in the study supports the findings of Mukherjee (2020), who claimed that during and after COVID-19, classroom size may shrink physically, however, virtual classrooms may attract huge participation. Now, the government of India and the government of the People's Republic of Bangladesh have encouraged all the higher education institutions (HEIs) to take appropriate steps to introduce the "Integrated University Information Management Platform." It is imminent that teachers and policymakers appreciate the important aspects of building a learning platform for students, which will realise maximum engagement. Educational sectors must prepare themselves during the COVID-19 pandemic by expanding their resources and prepare themselves for using several learning methods to ensure wide learning and participation of the students as reported by Mukherjee and Hasan (2020). This is the first-ever case that applied a cross-border experimental approach across one of the Indian and Bangladesh universities to understand the effectiveness of the e-learning framework and provide useful data for analysis. Real-time feedback on the performance of the virtual learning platform for videoconferencing and the transportation network was gathered via the central portal, which could be further investigated. The situation was useful for research purposes because this qualitative data could be contrasted with the interactions experienced by the students. Second, the comments 
and impressions of the students from these learning sessions were assessed through multiple literature reviews and question-based surveys that provided valuable insights and immensely contributed to the growing body of literature on design thinking and learning continuity. Because subjective metrics are not so easy to achieve, these questions focused on two aspects: the general impression of the new technology and the use of videoconferencing in the specific virtual learning session. The study results support the propositions provided by Mukherjee and Hasan (2020), who opined that there is a requirement of a policy framework in the primary, secondary, and tertiary education for using a blended learning model, having the advantage of self-paced learning in a virtual environment, which is appropriate during and after the COVID-19 unforeseen situations. Third, this case study adopted experimental research as Tripura University's Business Management Department implemented Moodle LMS first and then the impression of the students on the technological quality of the learning sessions, such as audio/video quality, instructional detail, etc. has been recorded. Our results showed that the students found the exercise interesting, and while the experiment was on, they were able to follow the lecture. It can be considered as a positive outcome, as during conventional lectures, the students tend to get distracted. The virtual classroom is an online program that offers a practical teaching and learning experience for users. The online curriculum would benefit both teachers and students. Moreover, the classroom atmosphere is more comfortable, as managing and finding resources and lectures becomes simpler. The findings of the study support the work of Barber, Donnelly, Rizvi and Summers (2013), who reported that the use of ICT tools and its collaboration with other platforms have drastically reformed the higher education learning framework with minimal requirement of place and physical availability of classrooms. In the area of learning and teaching, making education more available could be a better solution. However, the main aim would be to build an online knowledge dissemination platform where students and teachers can work together and obtain teaching and learning benefits. COVID-19 has offered an opportunity to study the impact of technology and its application as a platform on knowledge dissemination and its effect on learning continuity (Lone, 2017). Further, the research community could study and explore how new technologies can serve as one of the key drivers to enable learning (Shea \& Bidijerano, 2009). Therefore, our study adopted a unique case-based experimental approach and the outcomes of this study will help future researchers in the area of higher education, especially in developing economies like India and Bangladesh. Future research studies can focus on adopting the same framework on a larger scale for the generalisation of the findings and may report on any other challenges. Learning gain has always been on the agenda of learning professionals, and developing a technology-mediated learning platform is quite pioneering for any public university, where policy level change warrants force of order and willpower, besides technology infrastructure and adequate training. 
The COVID-19 pandemic attempted to disrupt the teaching-learning process during lockdown; nevertheless, the success of these two institutions run into glory not only through technology enhancement but also through lower absenteeism percentage, with even a hundred percent attendances on some days. What is more, the integration of Moodle LMS with online classes in the Department of Business Management at Tripura University and a similar approach at the Institute of Business Administration at Dhaka University have elevated the andragogic infrastructure, independent of a physical classroom, thereby ensuring learning continuity ubiquitously. Under the COVID-19 pandemic situation, online learning has become the most significant part of higher education institutions, which is further supported by three-quarters of the university top authorities who believe that online learning is better than personal learning (Allen \& Seaman, 2014). This pandemic has caught the worldwide citadels of academic leadership off-guard, particularly the erstwhile successful teaching styles that suddenly went futile. Mere ad-hoc use of technology intermittently defeated the purpose of blended learning in the past and these two departments have augmented the virtual environment as a part of their design thinking strategy within the scope of the curriculum and rendering academic delivery with higher engagement and monitoring thus ensuring higher learning gain. The arguments of technology overtures may not stand true in the light of a structured curriculum and responses received from the students thereof.

\section{CONCLUSION}

Students experienced the blended teaching approach well; most importantly, all students were inspired to complete their respective courses. The videoconferencing tools play theoretical as well as practical roles in the process of teaching and learning. However, teaching and learning technology using design thinking is another approach, which directly affects the education sector, and shows the importance of teaching review plans. The education sector needs to be reorganised as India and Bangladesh slowly move towards fulfilling their dream of becoming digitised countries. Using digital teaching aids like virtual classrooms, Learning Management System (LMS), and messaging applications, the teachers can extend a collaborative learning experience to the students.

In turn, students can create smaller learning cohorts in the digital space and consume the learning resources as shared by the teachers. More importantly, the continuous evaluation grade sheets are available to use within every LMS to enable the teachers to develop a temporal as well as a cross-sectional view of the class performance indicating the learning gain of the students at the cohort as well as at the individual level. Online classrooms require different pedagogical approaches to teaching from traditional and typical "chalk and talks." It is a big challenge to bring a change to the norm. 
Although the cycle of improving teaching methods may be quicker for developing economies because of their cultural acceptance and advances in technology (Kort \& Reilly, 2001), in a developing country such as India and Bangladesh, institutional culture cannot be expected to shift overnight and it will take its own time and space.

Nonetheless, to become next-generation universities, all higher education institutions (HEIs) in India and Bangladesh need to create a major transition to digital education. First of all, it requires adequate teacher preparation to build an understanding of the latest advances in teaching and technology applied worldwide. Teachers should be motivated to embrace modern pedagogy and switch from teacher-centric to student-centric approaches in teaching and learning (Mascolo, 2009).Higher education institutions should provide teachers with instructions on using various technical supports to build an effective learning atmosphere. With the goal of creating a more immersive and collaborative learning atmosphere, teachers will be motivated to update their courses and integrate virtual classrooms into all classes. It is also important to ensure that every online educational platform selected conforms to the present curriculum and context of the institution. An essential element of using the online classroom for educational purposes is that it needs to be commercially feasible, meaning that consumers can have the services at very little cost (Bower, 2006).It is a cost-effective scheme and a simple solution to fostering immersive learning at HEIs in India and Bangladesh, as creating a virtual classroom doesnot entail major money investments. By combining physical and online teaching modes, it allows for an immersive learning environment for students. This study aims to describe the understanding of the students in an instructional course about the virtual classroom and the virtual classroom features and characteristics they find most helpful for further learning uses. The findings suggest that the majority of the virtual classroom features were favourably regarded by the students who explicitly listed convenient access to the instructor's course and online teaching functions as key benefits of the virtual classroom. One significant advantage of the virtual classroom, according to Jonassen and Reeves (1996), is that it provides two-way communication for both learners and teachers. Learners may conveniently access the curriculum through an online system and educators can provide immediate feedback for any queries the learners may have regarding the course content. That implies the online classroom can help the learners get "only-in-time feedback" from the professor of the course. Further specific benefits of the online classroom are that it allows users to learn at their speed, because they may pause, rewind, replay, and record video or audio lessons easily. Students not attending formal classes because of sickness or disability may listen or watch the lectures they have enrolled in.

Moreover, most respondents also indicated that the online classroom helps them to access study materials, assignments, quizzes, and to interact with the members of the class under the same cohort by joining in group discussions. The findings of this study corroborate the previous work of the 
researchers, which showed that virtual classrooms could play an important role in improving the students' learning and achievements. Firstly, the analysis was performed on respondents from two academic institutions, and the sample size was small and restricted, the expanded research would provide additional analytical data. The study has established that learner's maturity and teacher's contribution to education using the design thinking approach yield a better response from the student community and ensure higher learning gain.

\section{REFERENCES}

[1] Allen, E., \& Seaman, J. (2014). Grade change: Tracking online education in the United States. Babson Survey Research Group and Quahog Research Group.

[2] Barber, M., Donnelly, K., Rizvi, S., \&Summers, L. (2013). An Avalanche Is Coming: Higher Education and the Revolution Ahead. Institute for Public Policy Research, London, UK. Retrieved November 20. 2020, from: https:/ / www.voced.edu.au/content/ngv\%3A55590

[3] Bates, A. (2005). Technology, E-learning, and Distance Education. Abingdon, UK: Routledge.

[4] Bower, M. (2006). Virtual classroom pedagogy.ACM SIGCSE Bulletin, 38(1), 148-152. https:// doi.org/10.1145/1124706.1121390

[5] Cross, N. (2006). Designerly Ways of Knowing. London: Springer-Verlag London.

[6] Dey, A. K. (2007).A lean approach to improve course curriculum of MBA.Business Perspective, 9(2), 109-128.

[7] Dong, A. (2015). Design 3 innovation: Perspective or evidence-based practices. International Journal of Design Creativity and Innovation, 3(3-4), 148-163. https://doi.org/10.1080/21650 349.2014.943294

[8] Dorst, K. (2011). The core of "design thinking" and its application.Design Studies, 32(6), 521-532. https://doi.org/10.1016/j.destud.2011.07.006

[9] Dreamson, N. (2017). Online collaboration in design education: an experiment in real-time manipulation of prototypes and communication. International Journal of Art and Design Education, 36(2), 188-199. https:// doi.org/10.1111/jade.12079

[10] Educational Benefits of Online Learning.(n.d.). Retrieved June 25, 2020 from: https://sphweb. bumc.bu.edu/otlt/teachingLibrary/Technology/online $\% 20 \%$ 20learning.pdf

[11] Edwards, F. R. (2018). The Relationship Between College Student Attitudes Towards Online Learning Based on Reading Self-Efficacy, Ethnicity, and Age. Retrieved March 12, 2020 from: https://digitalcommons.liberty.edu/doctoral/1729/

[12] Gaikwad, A., \&Randhir, V. S. (2016). E-learning in India: Wheel of change. International Journal of E-Education, e-Business, e-Management and e-Learning, 6(1), 40-45. https://doi. org/10.17706/ijeeee.2016.6.1.40-45

[13] Gillies, D. (2008).Student perspectives on videoconferencing in teachereducation at a distance. Distance Education, 29(1), 107-118. doi: https://doi.org/10.1080/01587910802004878

[14] IDEO. (2013, April). Design Thinking for Educators. Retrieved June 17, 2020 from: https:// www.ideo.com/post/design-thinking-for-educators

[15] Jonassen, D., \& Reeves, T. (1996). Learning with technology: Using computers as cognitive tools. In D. Jonassen (Ed.), Handbook of research for educational communications and technology (pp. 694-719). New York: Macmillan.

[16] Kop, R., \& Hill, A. (2008).Connectivism: Learning theory of the future or vestige of the past? International Review of Research in Open and Distance Learning, 9(3). doi: https://doi. org/10.19173/irrodl.v9i3.523

[17] Kort, B., \& Reilly, R. (2001, July). Evolving educational pedagogy in developing nations. In Digital Nations Symposium at the MIT Media Lab (pp. 1-8).

[18] Kruger-Ross, M. J., \& Waters, R. D. (2013). Predicting online learning success: Applying the situational theory of publics to the virtual classroom. Computers and Education, 61(1), 176-184. doi: https://doi.org/10.1016/j.compedu.2012.09.015 
[19] Lawson, T., \& Comber, C. (2005). DfES Effective video conferencing in the classroom Summary report from six case studies. Retrieved May 20, 2020 from: http://dera.ioe. ac.uk/1611/

[20] Lone, Z. (2017).Impact of online education in India. International Journal of Engineering Science and Computing, 7(7), 13590-13592.

[21] Luecke, R. (2003). Harvard Business Essentials: Managing Creativity and Innovation. Harvard Business Press.

[22] Martin, F., \& Parker, M. (2014). Use of synchronous virtual classrooms: Why, who, and how? Journal of Online Learning and Teaching, 10(2), 192.

[23] Mascolo, M. (2009). Beyond student-centered and teacher-centered pedagogy: Teaching and learning as guided articipation. Pedagogy and the Human Sciences, 1(1), 3-27.

[24] Matthews, J., \& Wrigley, C. (2017).Design and design thinking in business and management higher education. Journal of Learning Design, 10(1), 41. https:// doi.org/10.5204/jld.v9i3.294

[25] Moore, M. G. (1989). Editorial : Three Types of Interaction, American Journal of Distance Education, 3:2, 1-7. doi: https:/ / doi.org/10.1080/08923648909526659

[26] Mostofa, S. M., Othman, R., Mukherjee, D., \& Hasan, K. K. (2020). A comprehensive framework of design thinking approach in knowledge management: A review in academic context. Journal of Education Culture and Society, 11(2),281-294. doi:https://doi.org/10.15503/ jecs2020.2.281.294

[27] Mukherjee, D. (2012a). Role of communication medium in web based instructional environment in Indian management education. Indian Journal of Open Learning, 21(1), 41-59.

[28] Mukherjee, D. (2012b). Blended learning model for management education in India - A critical review.3D- IBA Journal of Management \& Leadership, (3)2, 88-93.

[29] Mukherjee, D. (2014). Factors of management education in India as perceived by learners and providers: An empirical study. Vision: The Journal of Business Perspective, 18(2), 73-80. https://doi.org/10.1177/0972262914527872

[30] Mukherjee, D. (2020, May 03). Use of Digital Infrastructure Will Liberate Learning from the Boundaries of Classrooms. Indian Observer Post. http://indianobserverpost.com/News-Detail.aspx?Article $=816 \& W e b U r l=$ web

[31] Mukherjee, D., \& Hasan, K. K. (2020). Challenges in learning continuity during the COVID19 pandemic: A methodological and thematic review. South Asian Journal of Management, 27(3), 56-78.

[32] Nunley, K. F. (2012). Have schools become historical museums? In: R. Sylwester \& D. Moursund (Eds.), Creating an Appropriate 21st Century Education (pp. 22-26). First Edition August 2012, Eugene, Oregon, USA: Information Age Education.

[33] Parker, M. A., \& Martin, F. (2010). Synchronous virtual classrooms: Student perceptions from an online and blended education course. 2010 International Conference on Technology for Education, T4E 2010, 6(1), 93-100. doi: https://doi.org/10.1109/T4E.2010.5550054

[34] Parkinson, M. (2018). 16 Strategies for Presenting Virtually. Retrieved July 15, 2020 from: https://www.td.org/magazines/td-magazine/16-strategies-for-presenting-virtually

[35] Peytcheva-Forsyth, R., Yovkova, B., \&Aleksieva, L. (2018).Factors affecting students' attitudes towards online learning - The case of Sofia University.AIP Conference Proceedings, 2048(December). doi: https://doi.org/10.1063/1.5082043

[36] Razzouk, R., \& Shute, V. (2012). What is design thinking and why is it important?. Review of educational research, 82(3), 330-348.

[37] Rosenberg, M. J. (2005). Beyond E-learning: Approaches and Technologies to Enhance Organizational Knowledge, Learning, and Performance. John Wiley \& Sons.

[38] Roussos, M., Johnson, A. E., Leigh, J., Vasilakis, C. A., Barnes, C. R., \& Moher, T. G. (1997). NICE: Combining constructionism, narrative and collaboration in a virtual learning environment. ACM SIGGRAPH Computer Graphics, 31(3), 62-63. doi: https://doi. org/10.1145/262171.262264

[39] Settles, B. (2012).Active learning. Synthesis Lectures on Artificial Intelligence and Machine Learning, 6(1), 1-114.

[40] Shea, P., \& Bidjerano, T. (2009).Community of inquiry as a theoretical framework to foster "epistemic engagement" and "cognitive presence" in online education.Computers and Education, 52(3), 543-553. doi: https:// doi.org/10.1016/j.compedu.2008.10.007 
[41] Songkram, N. (2015). E-learning system in virtual learning environment to develop creative thinking for learners in higher education. Procedia - Social and Behavioral Sciences, 174, 674-679. https://doi.org/10.1016/j.sbspro.2015.01.600

[42] Suh, H. (2011). Collaborative learning models and support technologies in the future classroom.International Journal for Educational Media and Technology, 5(1), 50-61. Retrieved July 15, 2020 from: http://jaems.jp/contents/icomej/vol5/IJEMT5.50-61.pdf

[43] Wedig, T. (2010).Getting the most from classroom simulations: Strategies for maximizing learning outcomes.PS - Political Science and Politics, 43(3), 547-555. doi: https://doi. org/10.1017/S104909651000079X

[44] Wrigley, C., \&Straker, K. (2017). Design thinking pedagogy: The educational design ladder. Innovations in Education and Teaching International, 54(4), 374-385. doi: https://doi.org/10.1 080/14703297.2015.1108214

\section{DECLARATION OF CONFLICTING INTERESTS}

The authors declare no potential conflict of interest concerning the research, authorship, and/or publication of this case.

\section{FUNDING}

The authors did not receive any financial assistance for this research, authorship, and/or publication of this case 